\title{
Rebound Hammer Tests of High-Strength Concrete: Effects of Internal Stress and the Shape of the Impact Area of the Test Specimens on the Measurement Results
}

\author{
Jiri Brozovsky ${ }^{1 *}$, Lenka Bodnarova ${ }^{1}$, Jiri Brozovsky jr. ${ }^{2}$ \\ ${ }^{1}$ Faculty of Civil Engineering \\ Brno University of Technology \\ Veveri 331/95, 60200 Brno, Czech Republic \\ 2 Faculty of Civil Engineering \\ VSB - Technical University of Ostrava \\ Ludvika Podeste 1875/17, 70833 Ostrava-Poruba, Czech Republic \\ * Corresponding author, e-mail: brozovsky.j@fce.vutbr.cz
}

Received: 16 January 2018, Accepted: 05 December 2018, Published online: 17 January 2019

\begin{abstract}
This study examines the factors affecting the results of non-destructive testing of high-strength concrete performed on cubes and on cylinders and examines the processing of calibration relations. Tests were performed with both a type $N$ and a type $L$ Schmidt impact hammer (with a standard impact energy of $2.205 \mathrm{Nm}$ and $0.735 \mathrm{Nm}$ respectively). The assessed factors were internal stress in a specimen and the shape of the impact area. Test specimens were loaded by a force corresponding to the stress in specimen $0 \%, 10 \%$, $20 \%, 30 \%$, and $50 \%$ from the expected compressive strength. Rebound numbers of the unloaded test specimens were significantly lower than those of the loaded specimens. Therefore, calibration relations and/or correction coefficients processed by measurements of unloaded specimens can be assessed as unsuitable. To process calibration relations, we recommend exerting internal stress in amounts of $15 \%$ to $20 \%$ of the expected compressive strength of the tested HSC samples. During the determination of the effect of the shape of the test area on the cylindrical test specimen, it was assumed that the rebound numbers on the plane and the round test area would be the same. However, the test results revealed that the rebound numbers in the differently shaped test areas were different. For Schmidt impact hammer type $\mathrm{N}$, the rebound numbers in the round test area were lower by 0.7 units on average, and for Schmidt impact hammer type $L$, the rebound numbers in the round test area were lower by 1.7 units on average compared to the plane test area rebound numbers.
\end{abstract}

\section{Keywords}

high-strength concrete (HSC), rebound hammer, calibration relations, loading, internal stress

\section{Introduction}

According to EN 206 [1], high-strength concretes (HSC) are concretes of strength class $\mathrm{C} 55 / 67$ and higher. To produce HSC (compressive strength above $80 \mathrm{MPa}$ ), microparticles (mostly micro-silica) are commonly used. Nowadays, cement technology is increasingly using nanoparticles instead of microparticles for HSC, such as carbon nano-tube (CNT), nano-silica, nano- $\mathrm{TiO}_{2}$, nano$\mathrm{Fe}_{2} \mathrm{O}_{3}$, and nano-cement. The increasing rate of production and use of HSC in structures necessitates an accurate assessment of the performance and properties of HSC $[2,3,4]$. To assess the compressive strength of concrete in a structure, a calibration relation between the rebound number and compressive strength must be available. Calibration relations for prediction of compressive strength of concrete, tested by the Schmidt rebound hammer, are listed in the technical literature, in standards or in technical data sheets. Results for normal-weight concrete are indicated in the technical literature [5-11] in standards [12]. For lightweight concrete, the results are indicated in $[13,14,15]$, and for HSC, the results are indicated in $[16,17,18]$. The use of calibration relations is limited by conditions during measurements. Different compressive strength values can be obtained from various calibration relations for the same rebound number. 
One of the significant factors is the force acting on a test specimen in the compression test machine during measurements using the rebound hammer. The rebound hammer method is one of most widely used non-destructive testing (NDT) methods for assessment of compressive strength of concrete, along with ultrasonic pulse velocity (UPV) measurements, and pull-out tests (Capo). The rebound hammer measurements can be performed on any of the four sides of a column and provides a rebound number, UPV measurements (direct transmission measured by placing the two transducers on opposite sides) provides a velocity in $\mathrm{m} / \mathrm{s}$, and pull-out test (Capo) provides a load in $\mathrm{kN}$. For the determination of concrete strength in a construction, not only individual non-destructive testing methods but also so-called combined non-destructive methods are used [6]. Combined non-destructive methods are based on two or more non-destructive methods. The parameters obtained from these methods more accurately characterise concrete strength. Using a combination of methods compensates for the limitations and uncertainty typical of each method. The most elaborate combined test method for testing the compressive strength of concrete is based on the use of a Schmidt rebound hammer and UPV method called SonReb. The testing methodology is specified in the RILEM recommendation [19]. Relations for determining the compressive strength from the UPV and rebound value are given in a number of expert publications [6, 20, 21, 22].

\section{Theoretical details}

\subsection{Internal stress and rigidity of specimens}

If the tested area of a concrete structure or tested specimen is relatively small (e.g. a cube with an edge of $150 \mathrm{~mm}$ or a cylinder of $150 \times 300 \mathrm{~mm}$ ), any movement of the tested sample during the examination will negatively affect the results and cause the rebound number to be lower. In such cases, according to Malhotra and Carino [23], the tested specimen must be loaded or firmly supported against any movement of specimens.

Mitchell and Hoagland's [24] study on normal-weight concrete indicated that rebound numbers depend not only on the magnitude of the loading force itself but on the specimen size as well. Based on Vivithkeyoonvong and Puwapattanachat's [25] conclusions, the rebound numbers increase along with the internal strength of the sample. The increase in the rebound number is not significant when the internal compressive stress attains $15 \%$ of the final concrete compressive strength.
The expected conditions of the concrete tested in structures correspond with normal concrete use; that is, substantially lower internal stress values are taken into account rather than the corresponding compressive strength - usually $30 \%-50 \%$ of the ultimate load [26]. Therefore, in normative documents for normal-weight concrete, the requirements for specimens' loading are indicated for testing of concrete in structures as well as for processing of the calibration relations needed for determining the compressive strength obtained using rebound hammers. The standard EN 12504-2 [22] indicates that the concrete components must be at least $100 \mathrm{~mm}$ thick and must be connected with the structure and that test specimens of a smaller size must be firmly supported during testing. According to CSN 731373 [12], the test cube should be loaded in the compression test machine by a force that corresponds to stress approximately $10 \%$ of the expected compressive strength. If cylindrical specimens not taken from a structure are tested, the procedure is as follows: test specimens are put on a thick steel plate, and then they are firmly fixed and measurements are taken on the cylinder upper surface using the rebound hammer. According to BS 1881-202 [27], for tests conducted using the N-type Schmidt rebound hammer, a load from 1 to $7 \mathrm{MPa}$ is exerted by the compressive test machine. The RILEM NDT 3 [28] directive states that test specimens (cylinder, cube) must be of a large size (e.g. a cube with the edge $150 \mathrm{~mm}$ ) to prevent any unexpected movement of the specimens in respect to the rebound action of the Schmidt rebound hammer. Test specimens should be loaded by a stress of $1 \mathrm{MPa}$ or must be fastened to a rigid base plate. Based on the document ACI 228.1R [29], the cylindrical test specimens should be loaded by a force that will exert a stress of $3 \mathrm{MPa}$. Brazilian standard NBR NM 78 [30] describe usage of cylindrical test specimens loaded by a force that corresponds to $15 \%$ of the expected compressive strength.

From the above, it is apparent that there is no unified requirement for the loading values (internal stress) needed for processing of calibration relations, and for more accurate coefficients obtained from non-destructive tests using rebound hammers and from destructive compressive strength tests conducted on test specimens. Different values of internal stress in a concrete structure or a test specimen may influence the results measured by a rebound hammer.

\subsection{Test specimen shape}

The standard test specimen for assessing compressive strength is a cube $(\mathrm{a}=150 \mathrm{~mm})$ in many European countries, but in the United States, Canada, or Brazil for 
example, cylinders (mostly $\mathrm{d}=150 \mathrm{~mm}, \mathrm{~h}=300 \mathrm{~mm}$ but also different dimensions are used) are normally subjected to tests. Rebound numbers measured by rebound hammers on cylinders and cubes may be different because the impactor falls with its entire surface on the tested area of the cube, whereas in the case of cylinders, the impactor falls on a rounded surface, and the contact area is smaller. In directives [1, 12, 22, 27, 30], test specimens in the shape of a cube and cylinder are used. The study examines the effects of internal stress on cubes and the shape of the impact area of a cylindrical test specimen on the measurement results using rebound hammers for HSC testing.

\section{Materials and methods}

\subsection{Test specimens}

HSC in strength classes C60/75, C80/95 and C90/105 were produced for testing. Compressive strength was within 37.6 $\mathrm{MPa}$ and $112.6 \mathrm{MPa}$, depending on the concrete age (2, 7, 28 days) and strength class (C60/75, C80/95, 90/105). Compressive strength after 28 days for concrete samples classes C60/75, C80/95 and C90/105 was $69 \mathrm{MPa}, 90 \mathrm{MPa}$ and $103 \mathrm{MPa}$ respectively. Only one concrete mix was used for casting samples for each strength class (the effect of batch-to-batch and within-batch variability is discussed in detail in [31]). Three cube test samples of concrete were used to determine the compressive strength of concrete for each given age and class of concrete. The loading effects of the test specimen were investigated on cubes with the edge $\mathrm{a}=150 \mathrm{~mm}$. Tests were conducted on specimens at the ages of 2, 7, and 28 days. Cylinders with parameters $d=150$ $\mathrm{mm}$ and $\mathrm{h}=300 \mathrm{~mm}$ were used for monitoring the effects of the test area. Measurements were taken at the ages of 7 and 28 days. Test cubes were prepared from concrete of all the three mentioned strength classes, though the cylinders were prepared in strength classes C80/95 and C90/105.

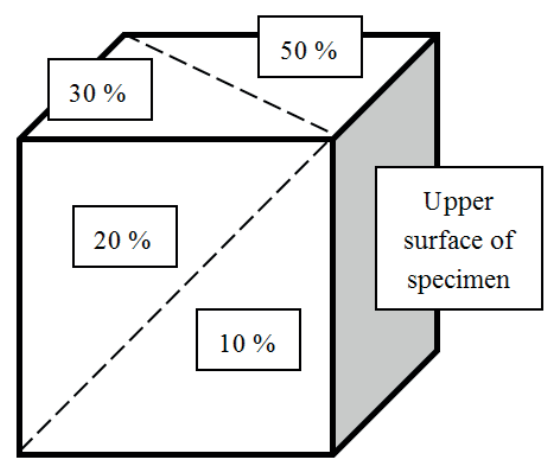

Fig. 1 Position of impact areas on a test specimen is schematically illustrated for measurement of rebound numbers at various loading values (internal stress)

\subsubsection{Test areas on cubes (monitoring the effects of specimens' loading on rebound numbers)}

Rebound numbers for every loading value were measured on two opposite sides of the test specimen. The distribution of impact areas for various loads is schematically represented in Fig. 1.

Prior to proper testing, the test areas were ground using a diamond wheel grinder until the concrete structure became apparent (procedure pursuant to CSN 731373 [12]; see Fig. 2b). To illustrate the condition of the test area after grinding it with an abrasive stone using the procedure from standard EN 12504-2 [22], see Fig. 2a.

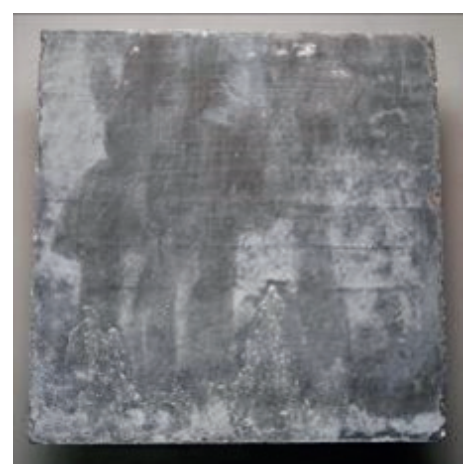

a) Test area adjusted using the procedure given in the EN 12504-2 [22] standard (abrasive stone)

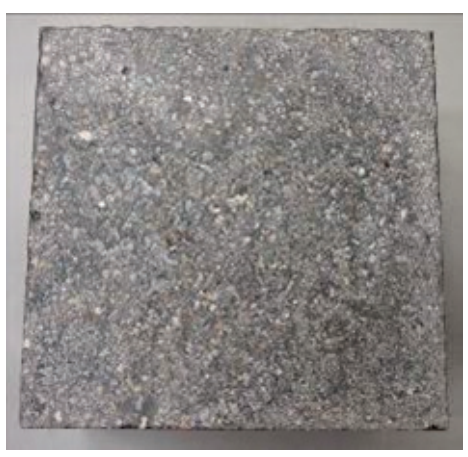

b) Test area adjusted using the procedure given in the CSN 731373 [12] standard (diamond wheel grinder)

Fig. 2 Details of the surface prepared for tests

\subsubsection{Test areas on cylindrical test specimens} (monitoring the effects of the shape of the impact area on rebound numbers)

Measurements were taken partly on a round test area (cylinder tangent) and partly on a plane test area (a stripe milled on the rounded surface of the cylinder specimen, along the entire height and along the width of $20 \mathrm{~mm}$ ). Positions of test points and impact areas on the cylindrical test specimens are given in Fig. 3. 


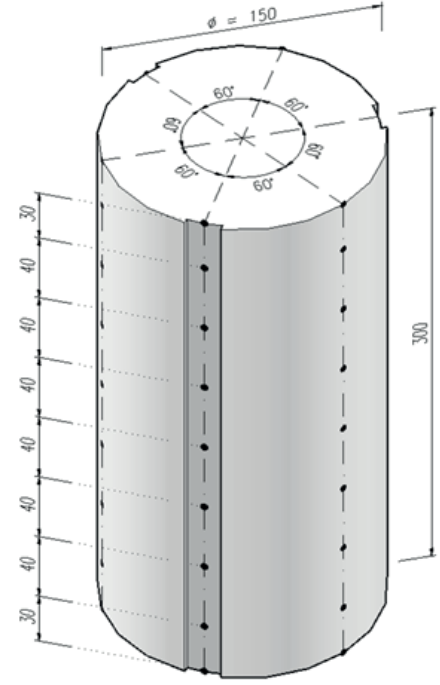

Fig. 3 Schematic illustration of the position of test points and areas on a cylindrical specimen

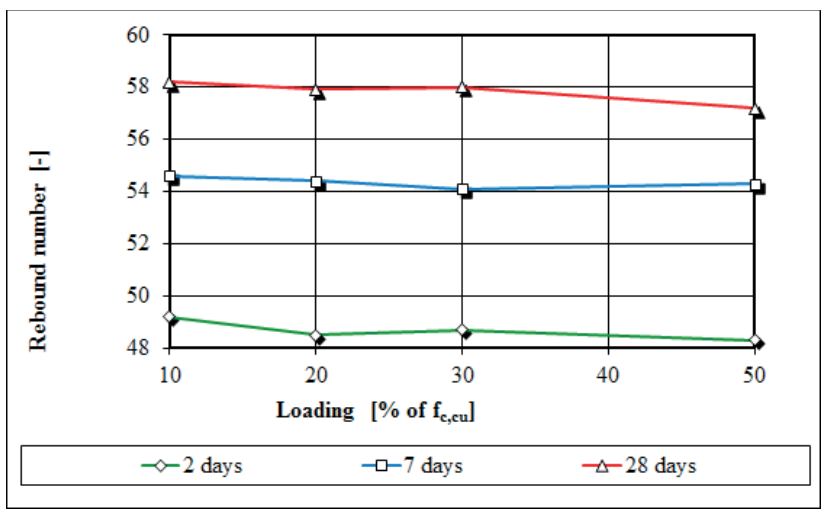

Fig. 4 The effects of rebound numbers, Schmidt rebound hammer type N

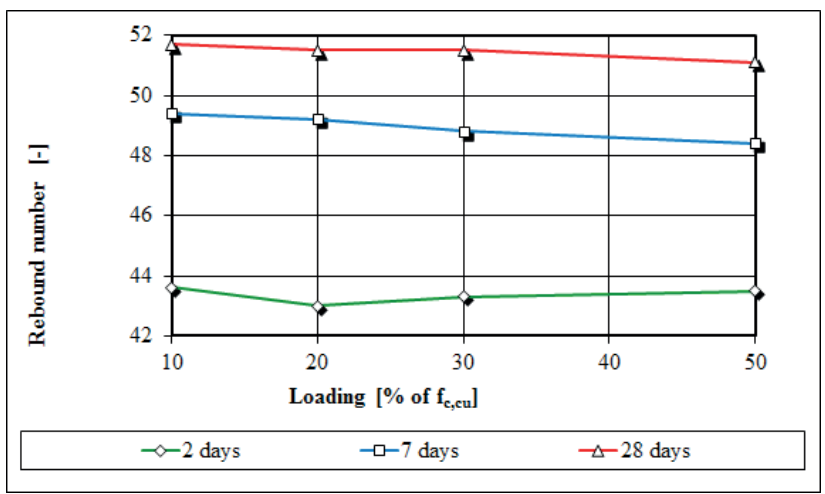

Fig. 5 The effects of rebound numbers, Schmidt rebound hammer type L

\subsection{Measuring procedure}

Schmidt impact hammer types $\mathrm{N}$ and L (standard impact energy of $2.205 \mathrm{Nm}$ resp. $0.735 \mathrm{Nm}$ ) were used.

To monitor the effects of internal stress, 7 rebound number measurements were taken for every test area; that is, 14 rebound numbers were available for each load. The position of the impact areas on a cube specimen are presented in Fig. 1.
To monitor the effects of the impact area on a cylindrical test specimen, 18 rebound measurements were taken on every type of test area. Two samples of concrete at the given ages were tested to determine the load of the cylindrical test specimens. Fig. 3 illustrates the test area distribution on a cylindrical specimen.

The values of rebound numbers that differed from the average by more than $14 \%$ were excluded in the case of the N-type Schmidt rebound hammer and by more than $13 \%$ in the case of the L-type Schmidt rebound hammer (see the standard requirements [12] and analysis conducted in [32]). A precondition limit was set up at 11 valid rebound numbers at each given load and at 15 valid rebound numbers at each given type of impact area. Measurements that met these criteria were used for further processing.

\section{Results and discussion}

\subsection{Effects of specimens' loading on rebound numbers}

Test specimens were loaded by a force corresponding to the stress in a specimen $0-10 \%-20 \%-30 \%-50 \%$ from the expected compressive strength. Average rebound numbers for each curing age and internal stress were within 43-64 (rebound hammer type $\mathrm{N}$ ) and within 37-57 (rebound hammer type L).

Testing of specimens in a zero-stress condition was ended after several series because of the considerable dispersion of the rebound numbers, which were substantially lower than the rebound numbers measured at $10 \%$ loading.

The effects of the specimens' loading rate on the rebound numbers are given in Fig. 4 (rebound hammer type $\mathrm{N}$ ) and Fig. 5 (rebound hammer type L).

Percentage differences of rebound numbers $\Delta \mathrm{R}_{\mathrm{i}-10}$ were calculated according to Eq. (1), and they are shown in Table 1 and Table 2. The calculation was based on the differences between the rebound numbers determined for test specimens loaded by $10 \%$ of the expected compressive strength and for test specimens loaded by $20 \%, 30 \%$, and $50 \%$ of the expected compressive strength.

$$
\Delta R_{i-10}=\frac{R_{i}-R_{10}}{R_{10}} \cdot 100 \quad[\%]
$$

Where,

$R_{10}$ - The impact hammer rebound number for test specimens loaded to $10 \%$ of the expected concrete compressive strength;

$R_{i}$ - The impact hammer rebound number for test specimens loaded to $20 \%, 30 \%$, and $50 \%$ of the expected concrete compressive strength. 
Table 1 Average percentage differences for rebound numbers for various HSC specimens' loading - Rebound hammer type $\mathrm{N}$

\begin{tabular}{lccc}
\hline \multirow{2}{*}{ Curing age of HSC } & \multicolumn{3}{c}{ Rebound hammer type N } \\
& $\Delta \mathrm{R} 20-10$ & $\Delta \mathrm{R} 30-10$ & $\Delta \mathrm{R} 50-10$ \\
\hline 2 days & -1.4 & -0.4 & -0.5 \\
7 days & -1.0 & -0.9 & -0.3 \\
28 days & -1.8 & -0.5 & -1.7 \\
\hline Mean value & -1.4 & -0.6 & -0.9 \\
\hline
\end{tabular}

Table 2 Average percentage differences for rebound numbers for various HSC specimens' loading - Rebound hammer type L

\begin{tabular}{lccc}
\hline \multirow{2}{*}{ Curing age of HSC } & \multicolumn{3}{c}{ Rebound hammer type $\mathrm{N}$} \\
& $\Delta \mathrm{R} 20-10$ & $\Delta \mathrm{R} 30-10$ & $\Delta \mathrm{R} 50-10$ \\
\hline 2 days & -1.4 & -0.4 & -0.4 \\
7 days & -0.7 & -1.2 & -0.4 \\
28 days & -0.2 & -2.0 & -1.2 \\
Mean value & -0.8 & -1.2 & -0.6 \\
\hline
\end{tabular}

The maximum rebound numbers were determined for loading values of $10 \%$ of concrete strength, and the values decreased subsequently. Differences between rebound numbers for loading values of $10 \%$ of the compressive strength and rebound numbers for loading values $20 \%$ to $50 \%$ of the compressive strength were within $-1.8 \%$ and $-0.3 \%$ for the N-type Schmidt rebound hammer and within $-2.0 \%$ and $-0.2 \%$ for the L-type Schmidt rebound hammer. For HSC specimens, the rebound numbers were usually within 40-65 units, and to these corresponding differences in rebound number 0.8 to 1.3 of unit. The actual stress in a structure depends on the applied load, but usually, it amounts from $30 \%$ to $50 \%$ of the expected compressive strength.

For processing of calibration relations for HSC, based on an analysis obtained from our measurements, we recommend loading test specimens in a compression test machine with a force ranging from $15 \%$ to $20 \%$ of the expected compressive strength. Experience gained for HSC is in compliance with the information indicated in the literature [23, 25] for normal-weight concrete. The recommendations given in standards [27, 33] or directive RILEM NDT 3 [28] are not suitable for processing calibration relations for HSC.

\subsection{Effects of test specimen shape (impact area) on rebound numbers}

To process calibration relations between rebound numbers and cylinder strength, some standards and technical literature use a procedure in which cylindrical specimens are fixed in the compression test machine, and measurements are taken on a rounded surface [28, 29, 30, 34, 35].
In our case, the rebound numbers were measured partly on a round test area and partly on a plane test area (a stripe milled on the rounded surface of the cylinder specimen along the entire height and along a width of $20 \mathrm{~mm}$ ). In determining the effect of the shape of the test area on the cylindrical test specimen when testing with a rebound hammer, it was assumed that the rebound numbers would be the same, that is, the rebound number in the plane test area would be equal to the rebound number in the round test area. A comparison of rebound numbers from different impact areas is shown in Fig. 6 (Schmidt rebound hammer type N) and Fig. 7 (Schmidt rebound hammer type L). The analysis of the test results - see Fig. 6 (Schmidt rebound hammer type N) and Fig. 7 (Schmidt rebound hammer type L) - show that the rebound numbers in test areas of different shapes on the cylindrical test specimen were different. For Schmidt's rebound hammer type N, the round test area rebound numbers were lower on average by 1.7 units compared to the plane test area rebound numbers (ranging from -1.1 to -2.1 units), and for Schmidt's rebound hammer type $\mathrm{L}$, the rebound numbers in the round test area were lower on average by 0.7 units compared to the rebound numbers in the plane test area (ranging from -0.4 . to -1.2 units). Dispersion of rebound numbers obtained in the round test area was 1.2 to 2 times higher than in the plane test area. The shape of the impact area on cylindrical test specimens will affect the measurement results obtained by rebound hammers, and when calibration relations are processed, the effect can be significant. The difference in the impact area shape of a cylinder was apparent in the strength dependence correlation coefficient between the rebound value and cylinder strength. Correlation coefficients of the relation processed from the measurements taken of a rounded test area were lower by 0.05 .

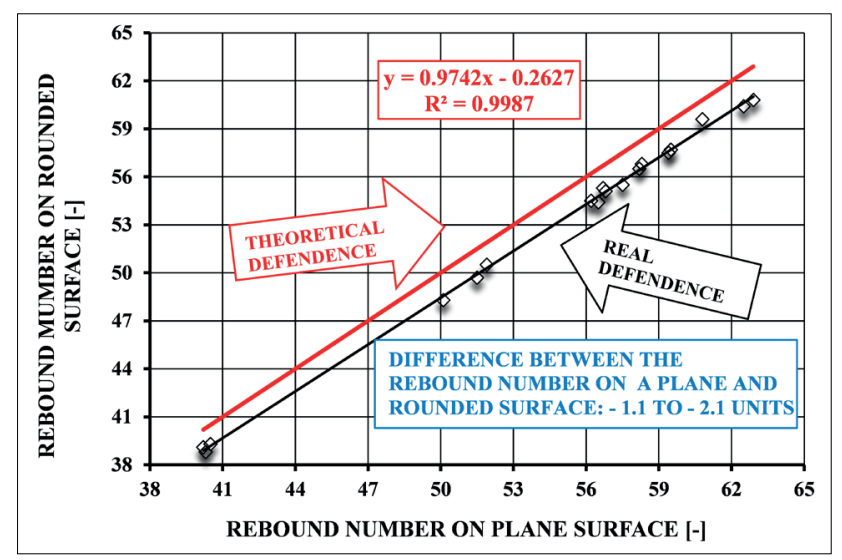

Fig. 6 Comparison of rebound numbers for various shapes of impact areas on a cylindrical test specimen - Schmidt rebound hammer type $\mathrm{N}$ 


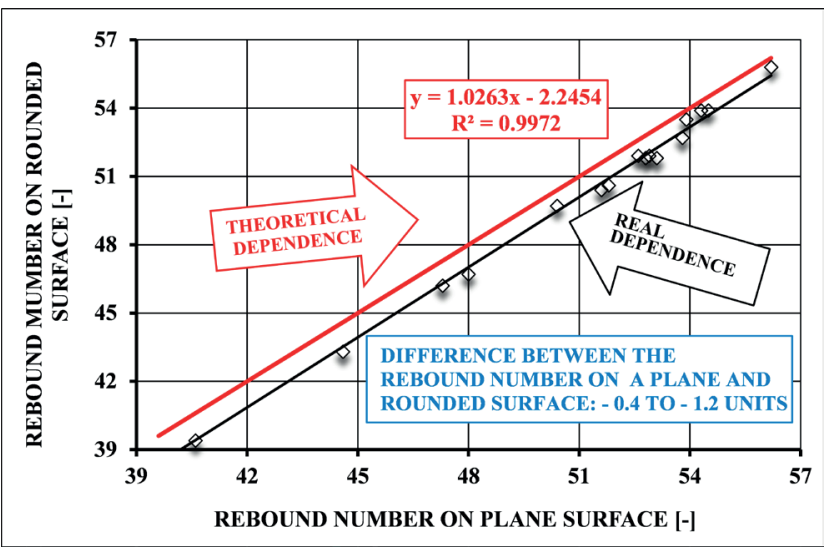

Fig. 7 Comparison of rebound numbers for various shapes of impact areas on a cylindrical test specimen - Schmidt rebound hammer type L

\section{Conclusions}

The effects of monitored factors were proven (internal stress in specimens and the impact area shape of the cylindrical test specimen) by measurement results using rebound hammers. These factors must be taken into consideration when calibration relations are processed for assessing HSC in structures.

(1) The effects of specimens' loading on the rebound number: Rebound numbers obtained on unloaded test specimens were substantially lower than those in loaded ones. Therefore, this procedure is needed for processing calibration relations, and/or more accurate coefficients can be evaluated as unsuitable. We recommend loading of HSC specimens, used for processing calibration relations, in a compression test machine with a force that exerts an internal stress corresponding to approximately $15 \%$ to $20 \%$ of the expected compressive strength.

(2) When a rebound hammer is used for measuring cylindrical specimens, the rebound numbers in a round area are lowered by approximately 1.7 , resp. 0.7 of the unit (depending on the rebound hammer standard impact energy) than on a plane area. Differences in compressive strength of HSC for 1 rebound number unit are approximately 3-5 $\mathrm{MPa}$. See the relations for the expected concrete strength calculations obtained from rebound hammer tests indicated in the literature [16].

\section{Acknowledgement}

This study was a part of the project GACR P104/15-23219S, 'Study of methods of nanoparticles dispersion, determination of conditions for preventing their re-agglomeration for application in cement composites', supported by the Czech Science Foundation and Project FAST-S-18-5410.

\section{References}

[1] EN 206:2013+A1:2016 E. "Concrete - Specification, performance, production and conformity", European Committee for Standardization, CEN, Brussels, Belgium, 2016.

[2] Ghafari, E., Costa, H., Júlio, E., Portugal, A., Durães, L. "The effect of nanosilica addition on flowability, strength and transport properties of ultra high performance concrete", Materials \& Design, 59, pp. 1-9, 2014.

https://doi.org/10.1016/j.matdes.2014.02.051

[3] Hela, R., Bodnarova, L., Florian, A., Sevelova, L. "High strength concrete with carbon nanotubes", In: Proc. of the 7th International Structural Engineering and Construction Conference, New Developments in Structural Engineering and Construction, Honolulu, Hawaii, USA, 2013, pp. 583-587.

[4] Sanchez, F., Sobolev, K. "Nanotechnology in concrete - A review", Construction and Building Materials, 24(11), pp. 2060-2071, 2010. https://doi.org/10.1016/j.conbuildmat.2010.03.014

[5] Breysse, D., Martínez-Fernández, J. L. "Assessing concrete strength with rebound hammer: review of key issues and ideas for more reliable conclusions", Materials and Structures, (47)9, pp. 1589-1604, 2014.

https://oi.org/10.1617/s11527-013-0139-9

[6] Breysse, D. "Nondestructive evaluation of concrete strength: An historical review and a new perspective by combining NDT methods", Construction and Building Materials, 33, pp. 139-163, 2012. https://doi.org/10.1016/j.conbuildmat.2011.12.103

[7] Almeida, I. R. "Emprego do esclerômetro e do ultra-som para efeito de avaliaçãoqualitativa dos concretos de alto desempenho", ("Use of sclerometry and ultrasound for the purpose of qualitative evaluation of high performance concretes"), Professor Thesis, Universidade Federal Fluminense, Rio de Janeiro, Brasil, 1993. (in Portuguese)

[8] Almeida, I. R. "Non-destructive testing of high strength concretes: rebound (Schmidt hammer and UPV), quality control of concrete structures", In: Quality Control of Concrete Structures, Proceedings of the Second International RILEM/CEB Symposium, 1st ed., CRC Press, London, UK, 1991, pp. 387-397.

[9] Facaoaru, I. "Romanian achievements in nondestructive strength testing of concrete", In: In Situ/ Nondestructive Testing of Concrete, American Concrete Institute, Farmington Hills, Michigan, USA, 1984, pp. 35-36.

[10] Lima, F. B., Silva, M. F. B. "Correlação entre a resistência à compressão do concreto e a suadureza superficial", (Correlation between the compressive strength and surface hardness of concrete), In: Proceeding of the 4th Congresso de Engenharia Civil, Juiz de Fora, Brasil, 2000, pp. 429-440. (in Portuguese).

[11] Nasser, K. W., Al-Manaseer, A. A. "Comparison of Nondestructive Testers of Hardened Concrete", ACI Materials Journal, 84(5), pp. 374-380, 1987.

[12] CSN 731373. "Nedestruktivni zkousení betonu - Tvrdomerne metody zkousení betonu", ("Non-destructive testing of concrete Determination of compressive strength by hardness testing methods"), Czech Office for Standards, Metrology and Testing, Prague, Czech Republic, 2011. (in Czech) 
[13] Tanyidizin, H., Coskun, A. "Determination of the principal parameter of ultrasonic pulse velocity and compressive strength of lightweight concrete by using variance method", Russian Journal of Nondestructive Testing, 44(9), pp. 639-646, 2008. https://doi.org/10.1134\%2FS1061830908090088

[14] Tjaronge, M. V. "Correlation of rebound number (r) from 1-type schmidt hammer and lightweight concrete strength", In: Proceedings of International Civil Engineering Conference, Surabaya, Republic of Indonesia, 2006, pp. 25-26.

[15] Brozovsky, J., Benes, D., Zach, J. "NDT of LWC with expanded clay", In: Nondestructive Testing of Materials and Structures, RILEM Bookseries, vol 6. Springer, Dordrecht, Netherlands, 2013. pp. 335-340.

https://doi.org/10.1007/978-94-007-0723-8 48

[16] Brozovsky, J. "High-strength concrete - NDT with rebound hammer: influence of aggregate on test results", Nondestructive Testing and Evaluation, 29(3), pp. 225-268, 2014. https://doi.org/10.1080/10589759.2014.926897

[17] Brozovsky, J., Prochazka, D., Benes, D. "Determination of high performance concrete strength by means of impact hammer", In: Procedings of the 10th International Conference of the Slovenian Society for Non-Destructive Testing, Application of Contemporary Non-Destructive Testing in Engineering, Ljubljana, Slovenia, 2009, pp. 233-241.

[18] Pascale, G., Leo, A. Di, Carli, R., Bonora, V. "Evaluation of actual compressive strength of high strength concrete by NDT", The e-Journal of Nondestructive Testing, 11, pp. 1-6, 2000.

[19] RILEM TC, "NDT 4 Recommendation for in situ concrete strength determination by combined non-destructive methods", In: RILEM Recommendations for the Testing and Use of Constructions Materials, E \& FN SPON, New York, NY, USA, 1994, pp 92-98.

[20] Breysse, D., Klysz, G., Dérobert, X., Sirieix, C., Lataste, J. F. "How to combine several nondestructive techniques for a better assessment of concrete structures?", Cement and Concrete Research, 38(6), pp. 783-93, 2008.

https://doi.org/10.1016/j.cemconres.2008.01.016

[21] ASTM 597. "Standard Test Method for Pulse Velocity Through Concrete", ASTM International, USA, 2009.

[22] EN 12504-2. "Testing concrete in structures - Part 2: Nondestructive testing - Determination of rebound number", European Committee for Standartization, CEN, Brusel, Belgium, 2012

[23] Malhotra, V. M., Carino, N. J. "Handbook on nondestructive testing of concrete", 2nd edition, CRC Press, Boca Raton, Florida, USA, 2004.

[24] Mitchell, L. J., Hoagland, G. G. "Investigation of impact tube concrete test hammer", Highway Research Board Bulletin, 305, pp. 14-27, 1961.
[25] Vivithkeyoonvong, S., Puwapattanachat, S. "Effect of internal compressive stress and direction of Schmidt hammer on compressive strength of concrete estimated by combined ultra-sonic pulse velocity and rebound hammer methods", Kasetsart Engineering Journal, 38(12), pp. 110-117, 2006.

[26] Zoldners, N. G. "Calibration and use of impact test hammer", ACI J. Proc., 54(2), pp. 161-165, 1957.

[27] BS 1881-202. "Testing Concrete. Recommendations for sur- face hardness testing by rebound hammer", British Standards Institution, London, United Kingdom, 1986.

[28] RILEM TC. "NDT 3 Recommendations for testing concrete by hard- ness methods", E\&FN SPON, London, United Kingdom, pp. 97-91, 1984.

[29] ACI 228.1R-03. "In-Place methods to estimate concrete strength", American Concrete Institute, Farmington Hills, Michigan, USA, 2003.

[30] NBR NM 78. "ConcretoEndurecido - Avaliação Da Dureza Superficial PeloEsclerometro De Reflexao", ("Hardened con- crete - evaluation of surface stiffness by reflex sclerometer"), Associação Brasileira de Normas Técnicas, Rio de Janeiro, Brazil, 1996. (in Portuguese)

[31] Breysse, D., Balayssac, J. P., Biondi, S., Borosnyói, A., Candigliota, E., Chiauzzi, L., Garnier, V., Grantham, M., Gunes, O., Luprano, V., Masi A., Pfister, V., Sbartai, Z. M., Szilagyi, K., Fontan, M. "Nondestructive assessment of in situ concrete strength: Comparison of approaches through an international benchmark", Materials and Structures, 50(133), pp. 1-17, 2017. https://doi.org/10.1617/s11527-017-1009-7

[32] Brozovsky, J., Matejka, O., Martinec, P. "Concrete interlocking paving blocks compression strength determination using non-destructive methods determination using non-destructive methods", In: Proceedings of the 8th International Conference of the Slovenian Society for Non-Destructive Testing, Application of Contemporary Non-Destructive Testing in Engineering, Portorož, Slovenia, 2005, pp. 91-98.

[33] EN 12390-3 "Testing hardened concrete - Part 3: Compressive strength of test specimens", European Committee for Standartization, CEN, Brussels, Belgium, 2009.

[34] Pavlik, A., Dolezel, J. "Non-destructive investigation of concrete structures", 1st ed., SNTL, Prague, Czech Republic, 1977. (in Czech)

[35] ISO 1920-7. "Testing of concrete - Part 7: Non-destructive tests on hardened concrete", Technical Committee: ISO/TC 71/ SC 1 Test methods for concrete, International Organization for Standardization, Geneva, Switzerland, 2004. 